\title{
Influence of Glass Fiber wt \% and Silanization on Mechanical Flexural Strength of Reinforced Acrylics
}

\author{
Rodrigo B. Fonseca ${ }^{1 *}$, Isabella N. Favarão ${ }^{2}$, Amanda V. B. Kasuya ${ }^{2}$, \\ Marcel Abrão ${ }^{3}$, Nícolas F. M. da Luz ${ }^{4}$ Lucas Z. Naves ${ }^{5}$ \\ ${ }^{1}$ Department of Operative Dentistry and Dental Materials, Dental School, Federal University of Goiás, Goiânia, Brazil \\ ${ }^{2}$ Dental School, Federal University of Goiás, Goiânia, Brazil \\ ${ }^{3}$ Dental School, Pontifical Catholic University of Minas Gerais, Belo Horizonte, Brazil \\ ${ }^{4}$ Dental School, State University of Londrina, Londrina, Brazil \\ ${ }^{5}$ Department of Dental Materials, Piracicaba Dental School, State University of Campinas, Piracicaba, Brazil \\ Email: *rbfonseca.ufg@gmail.com
}

Received December 11, 2013; revised January 11, 2014; accepted January 18, 2014

Copyright (c) 2014 Rodrigo B. Fonseca et al. This is an open access article distributed under the Creative Commons Attribution License, which permits unrestricted use, distribution, and reproduction in any medium, provided the original work is properly cited. In accordance of the Creative Commons Attribution License all Copyrights @ 2014 are reserved for SCIRP and the owner of the intellectual property Rodrigo B. Fonseca et al. All Copyright (C) 2014 are guarded by law and by SCIRP as a guardian.

\begin{abstract}
The aim is to evaluate the flexural strength of acrylic resin bars depending on the addiction of glass fibers with or without previous 3-methacryloxypropyl-trimethoxysilane (silane) application. Short fibers $(3 \mathrm{~mm})$ were treated and added to an acrylic resin powder, being further mixed with acrylic liquid to create bars $(25 \times 2 \times 2 \mathrm{~mm})$ of 11 experimental groups $(\mathrm{N}=10)$, according to the interaction of experimental factors: weight $\%$ of glass fibers: $(0.5 ; 1 ; 3 ; 4 ; 6$ and 7$)$ and silane application (with silane (S) or without silane (N)). Flexural strength and scanning microscopy evaluation were performed (SEM). Data (MPa) were submitted to ANOVA and Tukey $(\alpha=5 \%)$. A significant difference between groups was observed $(p=\mathbf{0 . 0 0 1}): \mathrm{S} 7 \%(128.85 \pm 35.76) \mathrm{a}, \mathrm{S6} \%(\mathbf{1 1 9 . 3 1} \pm 11.97) \mathrm{ab}$, S4\% (116.98 \pm 25.23$)$ ab, N4\% (107.85 \pm 24.88$)$ abc, S1\% (96.29 \pm 20.65$) b c$, S0.5\% (89.29 \pm 7.33$) c d, ~ S 3 \% ~(89.0 \pm$ 11.27)cd, N3\% (86.79 \pm 17.63)cd, N1\% (85.43 \pm 16.44$)$ cd, Control (73.29 \pm 25.0$)$ de, N0.5\% (59.58 \pm 19.46$)$ e. For $N$ groups, it was not possible to include more than $4 \%$ wt fibers. SEM showed better fiber-resin interaction for $\mathrm{S}$ groups, and fractures around fibers on $\mathbf{N}$ groups. Previous silane application enables the addiction of greater quantity of glass fibers and better interaction with the acrylic resin resulting in higher flexural strength. Without silane, fibers seem to act as initial crack points due to poor interaction.
\end{abstract}

\section{KEYWORDS}

Glass Fibers; Silane; Flexural Strength; Acrylic Resin; Reinforcement

\section{Introduction}

Acrylics' fracture due to high transitory force caused by an accident or a small force during repeated mechanical load [1] is a direct result of development and propagation of cracks in the areas of stress concentration [2]. The chances of fractures can be reduced increasing the strength of polymethyl methacrylate (PMMA), typically used in dentistry for provisional restorations or removable prosthesis.

After many attempts to improve the mechanical properties of PMMA resins, interest has turned to fiber rein-

*Corresponding author. forcement. The incorporation of fibers into polymer matrix has provided substantial improvements on flexural strength and fatigue resistance of composite resin materials [3-5]. The fiber reinforcing mechanism has been explained by the principle that a relatively soft ductile polymer matrix is fully capable of transferring an applied load to fibers via shear forces at the interface [3].

Among many types of reinforcement, glass fiber stands out for presenting high tensile strength and favorable esthetic qualities [6,7], being tested into dental polymers for over 30 years [8]. The effectiveness of fiber reinforcement is influenced by many variables including the quantity of fibers $[9,10]$, their length $[9,11]$, direction 
[9], form [12], orientation [6], position [6], adhesion to the polymer matrix [6], impregnation with the resin [13], and the type of resin [9].

Studies have demonstrated a direct relationship between the fiber content and the flexural and impact strength of the reinforced resin [14,15], according to the law of mixtures [16]. However, through the use of 3\% (by weight) of many types of fibers without any surface treatment, Dogan et al. [17] reported no structural reinforcement of acrylic resin bars.

The silane coupling agent treatment (3-methacryloxypropyl-trimethoxysilane) creates a siloxane network with the hydroxyl $(\mathrm{OH})$ of the $\mathrm{Si}$ in the glass fiber surface and co-polymerize with the acrylic resin [18]. Silanized glass fibers present a higher surface energy and tend to be better impregnated, resulting in better adhesion to polymer matrix [19-21]. It is expected that more fiber content would be included into the acrylic resin after fiber silane treatment, resulting in better flexural strength.

The aim of this study was to evaluate the flexural strength of acrylic resin bars by varying the weight content of fibers and surface treatment with silane coupling agent.

\section{Materials and Methods}

The materials used in this study are listed in Table 1. Eleven test groups ( $\mathrm{n}=10$ per group) were created, representing the combination of factors in study: weight proportion of fibers $(0.5 \%, 1 \%, 3 \%, 4 \%, 6 \%, 7 \% \mathrm{wt})$, surface treatment (with silanization (S) and without silanization (N)) and a control group. For $\mathrm{N}$ groups it was not possible to include more than $4 \%$ wt fibers.

\subsection{Preparation of Specimens}

Standardized rectangular specimens were created with dimensions of $25 \mathrm{~mm}( \pm 2.0) \times 2 \mathrm{~mm}( \pm 0.1) \times 2 \mathrm{~mm}$ $( \pm 0.1)$, according to ISO4049/2000 [22]. Fibers (3 mmlong) were weighted on an analytical balance (HR-200, A\&D Company Limited, Japan) and mixed with the acrylic resin powder, either after silane treatment for 1 $\mathrm{min}$ at room temperature (S groups) or no silane treatment ( $\mathrm{N}$ groups).

Table 1. Materials used in this study.

\begin{tabular}{ccc}
\hline Material & $\begin{array}{c}\text { Batch } \\
\text { number }\end{array}$ & Manufacturer \\
\hline Pureglassfiber & $* *$ & $\begin{array}{c}\text { Maxxi Rubber, São Paulo, } \\
\text { Brazil }\end{array}$ \\
Silane (couplingagent) & 10916 & $\begin{array}{c}\text { Angelus Indústria de } \\
\text { Produtos Odontológicos S/A, } \\
\text { Londrina, Brazil }\end{array}$ \\
Self-polymerizedacrylicresin & 030211 & $\begin{array}{c}\text { Artigos Odontológicos } \\
\text { Clássico Ltd, São Paulo, } \\
\end{array}$ \\
\hline
\end{tabular}

The acrylic resin was then manipulated following manufacturer's powder/liquid ratio. The specimen mold was covered with a clean glass slab to remove excess resin and kept at room temperature for 20 minutes under $9.8 \mathrm{~N}$ load until polymerization of the resin was completed. After preparation specimens were finished with 600, 1000 and 1200 grit SiC paper (Norton, São Paulo, SP, Brazil) under water stream. All specimens were stored in distilled water at $37^{\circ} \mathrm{C}$ for 24 hours before testing.

\subsection{Flexural Strength Test}

Specimens were positioned on a 3-point bending flexural strength testing apparatus (K5005 MP; Kratos, Cotia, SP, Brazil) with two supports $20 \mathrm{~mm}$ apart, and tested at a crosshead speed of $1 \mathrm{~mm} / \mathrm{min}$. The load at fracture was recorded in Newtons and Flexure Strength (FS) was calculated in MPa with the following equation: $\mathrm{FS}=\mathrm{PL} / \mathrm{wb}^{2}$, where "P" is the maximum load at fracture, " $\mathrm{L}$ " is the distance between the supports $(20 \mathrm{~mm})$, "W" is the sample thickness and " $\mathrm{b}$ " the height. The samples' thickness and height were measured with a digital caliper (Mitutoyo, Japan).

\subsection{Scanning Electron Microscope (SEM) Examination}

Random samples were selected from each group and analyzed with a SEM. The samples, fixed on metal stubs, were placed in an ultrasonic bath of deionized water for 10 minutes, and then sputtered with gold (1 cycle of 120 s), under vacuum, in a sputtering device (MED 010; Balzers Union, Balzers, Liechtenstein). The surfaces were analyzed by SEM (LEO 435 VP; LEO Electron Microscopy Ltd., Cambridge, UK), focusing on the fracture features, integrity, and homogeneity along the interfaces between reinforcement material and acrylic resin. Samples were examined under magnification varying from $\times 250$ to $\times 10,000$. The unit operated at $20 \mathrm{kV}, \mathrm{WD}=$ $15-18 \mathrm{~mm}$, and with a spotsize range of $25 \mathrm{pA}$ to 100 pA.

\subsection{Statistical analysis}

Statistical analysis was firstly performed with a factorial analysis $(2 \times 4)$ including the fiber surface treatment (S and $\mathrm{N})$ versus fiber wt\% $(0.5 ; 1.5$; 3 and 4$)$ with a general linear model procedure in SSPS17.0 (SPSS Inc., Chicago, USA). After that all groups were submitted to Kolmogorov-Smirnov test of normal distribution, oneway ANOVA and Tukey Honestly Significant Difference (HSD). All tests were performed at 5\% level of significance.

\section{Results}

The factorial analysis showed no interaction between 
factors in study ( $p=0.267)$. Further ANOVA and Tukey tests showed significant difference between groups ( $p=$ 0.001; Table 2). The highest reinforcement effect was presented by S7\% group, but similar to S6\%, S4\% and $\mathrm{N} 4 \%$. N4\% group was similar to S1\%, which in turn was similar to S0.5\%, S3\%, N3\% and N1\% groups. N 0.5\% presented the lowest strength value, similar to the control group (C).

SEM analysis showed $\mathrm{N}$ groups with areas of poor interaction between glass fiber and acrylic resin with the presence of empty spaces (Figures 1(B) and 1(D)), suggesting potential sources for crack propagation. In $\mathrm{S}$ groups this situation was not found, showing better micromechanical/adhesive interlocking due to resin remnants at the fiber surface (Figure $\mathbf{1}(\mathrm{A})$ ) and a multi plane fracture at the fiber seen in Figure 1(C). Images of $S$ groups also showed the fracture line in more than one plane, suggesting better resistance for crack propagation (Figure 2(A)). The opposite occurred in $\mathrm{N}$ groups where the rupture line occurred in only one plane, showing lower resistance for crack propagation (Figure 2(B)).

\section{Discussion}

Fibers are known to reinforce dental polymers [6,23] and the present study compared the strengthening effect of including different weight proportion of fibers with or without surface treatment with a silane coupling agent. It was initially hypothesized that after silanization, the glass fiber reinforcement would be better wetted by the PMMA resin, facilitating the inclusion of a highest quantity of fiber and improving the final strength. The results

Table 2. Flexural Strength-means and standard deviations (MPa) for different \%wt of glass fiber and surface treatments.

\begin{tabular}{cc}
\hline Groups & Mean (SD) \\
\hline S7\% & $127.85(35.76)^{\mathrm{A}}$ \\
S6\% & $119.31(11.97)^{\mathrm{AB}}$ \\
S4\% & $116.98(25.23)^{\mathrm{AB}}$ \\
N4\% & $107.85(24.88)^{\mathrm{ABC}}$ \\
S1\% & $96.29(20.65)^{\mathrm{BC}}$ \\
S0.5\% & $89.29(7.33)^{\mathrm{CD}}$ \\
S3\% & $89.00(11.27)^{\mathrm{CD}}$ \\
N3\% & $86.79(17.63)^{\mathrm{CD}}$ \\
N1\% & $85.43(16.44)^{\mathrm{CD}}$ \\
C & $73.29(25.01)^{\mathrm{DE}}$ \\
N0.5\% & $59.58(19.46)^{\mathrm{E}}$ \\
\hline
\end{tabular}

Different capital letters mean significant differences within the same reinforcement $(p<0.05)$.

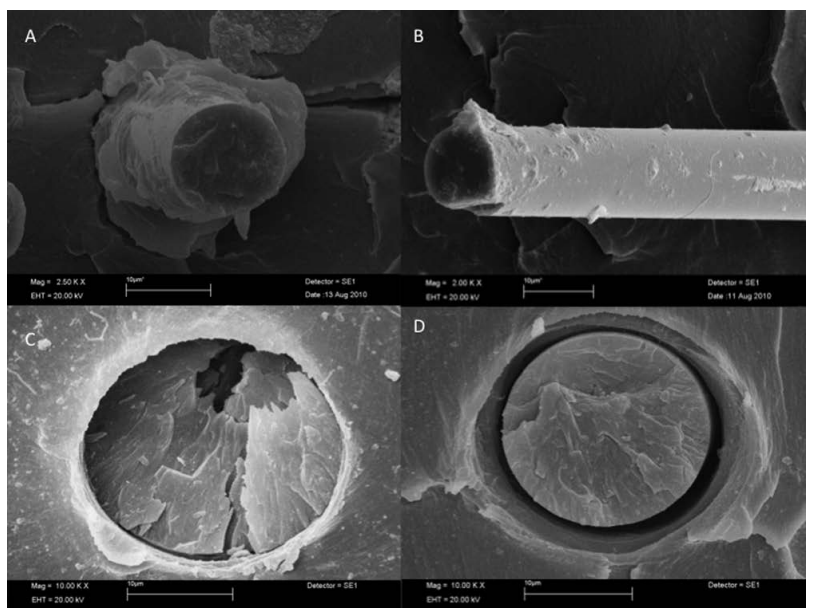

Figure 1. (A) (×2500 magnification) S4\% group showing a glass fiber surface surrounded by the PMMA resin; (B) $(\times$ 2,500 magnification) $\mathrm{N} 1.5 \%$ group showing a clean glass fiber as a result of] poor interaction with the resin matrix; (C) ( $\times$ 10,000 magnification) Silanized fiber (S3\% group) showing a multi plane fracture and an adhesive interaction with the resin; (D) $(\times 2500$ magnification $)$ Non silanized fiber surface (N1.5\% group) dislodged from the resin matrix with signals of reduced micromechanical/adhesive interlocking with resin.

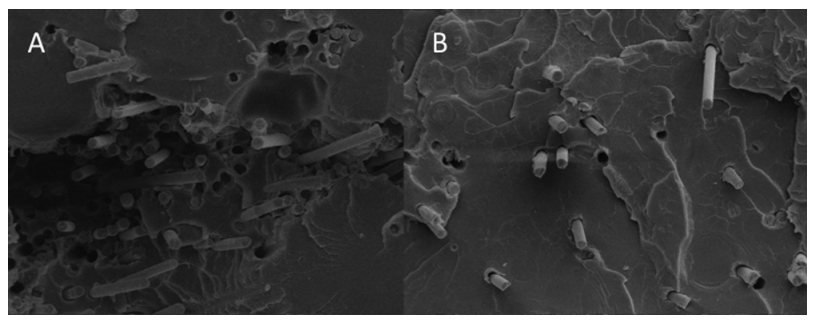

Figure 2. Rupture plane of fracture specimens. (A) $(\times 250$ magnification) $\mathrm{S6} \%$ group showing a multi plane fracture, suggesting better resistance for crack propagation; (B) ( $\times 250$ magnification) $\mathbf{N 4 \%}$ group with rupture occurring in only one plane, a signal of easier crack development.

of this work showed that the use of silanized glass fiber reinforcement significantly allowed more fibers to be included, increasing flexural properties, confirming this hypothesis. Fiber-to-resin interaction may be the reasons for these results.

Glass fiber is an inorganic substance based on alumina-lime-borosilicate, considered to be the predominant reinforcement for a polymer matrix due to their high mechanical properties, low susceptibility to moisture absorption, resistance to chemicals, thermal stability and high melting point $[5,20]$. Besides these characteristics, glass fibers are hydrophobic in nature and have low surface energy so that their natural compatibility with PMMA tends to be poor [21]. Untreated fibers could act as foreign bodies in the acrylic resin mixture and, instead of a strengthening effect, they would actually weaken the 
resin by breaking up the homogenous matrix [24]. This fact could be observed in this study, since N3\%, N1\% and N0.5\% groups presented flexural strength similar to C group. N4\% group was the only one that had a significant high strength when compared to samples with no reinforcement ( $\mathrm{C}$ group). This might be explained by the greater amount of fiber included in this group, as described by Behr et al. [16].

The silane coupling agent treatment increases fiber's surface energy [19] resulting on better impregnation by the polymer matrix (Figures 1(A) and 1(C)). This occurrence resulted in significant higher flexural strength obtained in specimens reinforced with silanized fibers compared to non-silanized ones. S7\%, S6\% and S4\% groups had flexural strength values significantly higher than control. The silanization of fibers enabled the inclusion of a greater quantity of fibers when compared to $\mathrm{N}$ groups. At $\mathrm{N}$ groups, any increase in fiber content beyond $4 \mathrm{wt} \%$ affected the flowability of the resin, so that fibers could not be mixed and prevented resin to react itself, producing a dry friable dough [21].

The reinforcing effect of the fibers is based on stress transfer from the polymer matrix to fibers but also the behavior of individual fibers acting as a crack stopper [25]. Figure 2(A) shows fracture line in more than one plane, demonstrating that an effective adhesion between fiber and resin can difficult crack development. The same could not be observed at $\mathrm{N}$ groups (Figure 2(B)) where a fracture line in only on plane was observed.

In general, acrylic resin reinforcement with glass fibers produced improved fracture strength. Provisional or even definitive prosthesis can successfully employ fiber reinforcement in order to assure better longevity and ease of repair [2]. The use of short random fiber presents itself as a less expensive and easy handling option for clinicians. Heat treatment of silanized glass to maximize the bonded strength is routinely performed in the glass industry, so heating the silane coupling agent after application into fibers could strengthening even more the PMMA resin, as seen in other studies for other materials $[26,27]$. Future research may focus on improving adhesion of fibers with heat treatment of silane in order to improve mechanical properties.

\section{Conclusions}

According to the results and limitations of the present study, it is possible to conclude:

1. The use of silane allows for greater inclusion of fibers, better interaction with the PMMA resin and higher flexural strength.

2. Without silane treatment, fibers seem to act as crack starter points due to poor interaction.

3. Silanized fibers can act as crack stopper.

\section{Acknowledgements}

The authors thank NAP/MEPA-Esalq-USP for support, assistance and availability of the laboratory and microscopy equipment which enabled the development of this research.

\section{REFERENCES}

[1] T. Kanie, K. Fujii, H. Arikawaand and K. Inoue, "Flexural Properties and Impact Strength of Denture Base Polymer Reinforced with Woven Glass Fibers,” Dental Materials, Vol. 16, No. 2, 2000, pp. 150-158.

http://dx.doi.org/10.1016/S0109-5641(99)00097-4

[2] D. C. Jagger, A. Harrisonand and K. D. Jandt, "The Reinforcement of Dentures," Journal of Oral Rehabilitation, Vol. 26, No. 3, 1999, pp. 185-194. http://dx.doi.org/10.1046/j.1365-2842.1999.00375.x

[3] S. H. Foo, T. J. Lindquist, S. A. Aquilino, R. L. Schneider, D. L. Williamsonand and D. B. Boyer, "Effect of Polyaramid Fiber Reinforcement on the Strength of 3 Denture Base Polymethyl Methacrylate Resins,” Journal of Prosthodontics, Vol. 10, No. 3, 2001, pp. 148-153. http://dx.doi.org/10.1111/j.1532-849X.2001.00148.x

[4] D. Jagger, A. Harrison, R. Jaggerand and P. Milward, "The Effect of the Addition of Poly(methyl methacrylate) Fibres on Some Properties of High Strength Heat-Cured Acrylic Resin Denture Base Material,” Journal of Oral Rehabilitation, Vol. 30, No. 3, 2003, pp. 231-235. http://dx.doi.org/10.1046/j.1365-2842.2003.01011.x

[5] J. John, S. A. Gangadharand and I. Shah, "Flexural Strength of Heat-Polymerized Polymethyl Methacrylate Denture Resin Reinforced with Glass, Aramid, or Nylon Fibers," Journal of Prosthetic Dentistry, Vol. 86, No. 4, 2001, pp. 424-427. http://dx.doi.org/10.1067/mpr.2001.118564

[6] S. R. Dyer, L. V. Lassila, M. Jokinenand and P. K. Vallittu, "Effect of Fiber Position and Orientation on Fracture Load of Fiber-Reinforced Composite,” Dental Materials, Vol. 20, No. 10, 2004, pp. 947-955. http://dx.doi.org/10.1016/j.dental.2003.12.003

[7] L. V. Lassilaand and P. K. Vallittu, "The Effect of Fiber Position and Polymerization Condition on the Flexural Properties of Fiber-Reinforced Composite," Journal of Contemporary Dental Practice, Vol. 5, No. 2, 2004, pp. 14-26.

[8] P. K. Vallittu, "A Review of Fiber-Reinforced Denture Base Resins,” Journal of Prosthodontics, Vol. 5, No. 4, 1996, pp. 270-276. http://dx.doi.org/10.1111/j.1532-849X.1996.tb00511.x

[9] H. D. Stipho, "Repair of Acrylic Resin Denture Base Reinforced with Glass Fiber," Journal of Prosthetic Dentistry, Vol. 80, No. 5, 1998, pp. 546-550. http://dx.doi.org/10.1016/S0022-3913(98)70030-7

[10] P. K. Vallittu, V. P. Lassilaand and R. Lappalainen, “Acrylic Resin-Fiber Composite. Part I: The Effect of Fiber Concentration on Fracture Resistance,” Journal of Prosthetic Dentistry, Vol. 71, No. 6, 1994, pp. 607-612. 
http://dx.doi.org/10.1016/0022-3913(94)90446-4

[11] T. A. Hamza, S. F. Rosenstiel, M. M. El-Hosaryand and R. M. Ibraheem, "Fracture Resistance of Fiber-Reinforced PMMA Interim Fixed Partial Dentures,” Journal of Prosthodontics, Vol. 15, No. 4, 2006, pp. 223-228. http://dx.doi.org/10.1111/j.1532-849X.2006.00110.x

[12] G. A. Geerts, J. H. Overturfand and T. G. Oberholzer, "The Effect of Different Reinforcements on the Fracture Toughness of Materials for Interim Restorations,” Journal of Prosthetic Dentistry, Vol. 99, No. 6, 2008, pp. 461467. http://dx.doi.org/10.1016/S0022-3913(08)60108-0

[13] P. K. Vallittu, "The Effect of Void Space and Polymerization Time on Transverse Strength of Acrylic-Glass Fibre Composite,” Journal of Oral Rehabilitation, Vol. 22, No. 4, 1995, pp. 257-261. http://dx.doi.org/10.1111/j.1365-2842.1995.tb00083.x

[14] P. K. Vallittu, "Comparison of Two Different Silane Compounds Used for Improving Adhesion between Fibres and Acrylic Denture Base Material,” Journal of Oral Rehabilitation, Vol. 20, No. 5, 1993, pp. 533-539. http://dx.doi.org/10.1111/j.1365-2842.1993.tb01640.x

[15] S. K. Garoushi, L. V. Lassilaand and P. K. Vallittu, "Short Fiber Reinforced Composite: The Effect of Fiber Length and Volume Fraction,” Journal of Contemporary Dental Practice, Vol. 7, No. 5, 2006, pp. 10-17.

[16] M. Behr, M. Rosentritt, R. Langand and G. Handel, "Flexural Properties of Fiber Reinforced Composite Using a Vacuum/Pressure or a Manual Adaptation Manufacturing Process,” Journal of Dentistry, Vol. 28, No. 7, 2000, pp. 509-514. http://dx.doi.org/10.1016/S0300-5712(00)00031-2

[17] O. M. Dogan, G. Bolayir, S. Keskin, A. Doganand and B. Bek, "The Evaluation of Some Flexural Properties of a Denture Base Resin Reinforced with Various Aesthetic Fibers," Journal of Materials Science: Materials in Medicine, Vol. 19, No. 6, 2008, pp. 2343-2349. http://dx.doi.org/10.1007/s10856-007-3343-8

[18] T. M. Chenand and G. M. Brauer, "Solvent Effects on Bonding Organo-Silane to Silica Surfaces,” Journal of Dental Research, Vol. 61, No. 12, 1982, pp. 1439-1443. http://dx.doi.org/10.1177/00220345820610121301
[19] P. K. Vallittu, "Curing of a Silane Coupling Agent and Its Effect on the Transverse Strength of Autopolymerizing Polymethylmethacrylate-Glass Fibre Composite," Journal of Oral Rehabilitation, Vol. 24, No. 2, 1997, pp. 124130. http://dx.doi.org/10.1046/j.1365-2842.1997.00464.x

[20] V. D. Kamble, R. D. Parkhedkarand and T. K. Mowade, "The Effect of Different Fiber Reinforcements on Flexural Strength of Provisional Restorative Resins: An In-Vitro Study,” Journal of Advanced Prosthodontics, Vol. 4, No. 1, 2012, pp. 1-6. http://dx.doi.org/10.4047/jap.2012.4.1.1

[21] T. K. Mowade, S. P. Dange, M. B. Thakreand and V. D. Kamble, "Effect of Fiber Reinforcement on Impact Strength of Heat Polymerized Polymethyl Methacrylate Denture Base Resin: In Vitro Study and SEM Analysis,” Journal of Advanced Prosthodontics, Vol. 4, No. 1, 2012, pp. 3036. http://dx.doi.org/10.4047/jap.2012.4.1.30

[22] Organization IS, ISO 4049, “Dentistry-Polymer Based Filling, Restorative and Luting Materials,” 2000.

[23] H. D. Stipho, "Effect of Glass Fiber Reinforcement on Some Mechanical Properties of Autopolymerizing Polymethyl Methacrylate,” Journal of Prosthetic Dentistry, Vol. 79, No. 5, 1998, pp. 580-584. http://dx.doi.org/10.1016/S0022-3913(98)70180-5

[24] G. S. Solnit, “The Effect of Methyl Methacrylate Reinforcement with Silane-Treated and Untreated Glass Fibers,” Journal of Prosthetic Dentistry, Vol. 66, No. 3, 1991, pp. 310-314. http://dx.doi.org/10.1016/0022-3913(91)90255-U

[25] R. C. Petersen, "Discontinuous Fiber-Reinforced Composites above Critical Length,” Journal of Dental Research, Vol. 84, No. 4, 2005, pp. 365-370. http://dx.doi.org/10.1177/154405910508400414

[26] C. Shen, W. S. Ohand and J. R. Williams, "Effect of Post-Silanization Drying on the Bond Strength of Composite to Ceramic,” Journal of Prosthetic Dentistry, Vol. 91, No. 5, 2004, pp. 453-458. http://dx.doi.org/10.1016/j.prosdent.2004.03.007

[27] N. Barghi, T. Berryand and K. Chung, "Effects of Timing and Heat Treatment of Silanated Porcelain on the Bond Strength,” Journal of Oral Rehabilitation, Vol. 27, No. 5, 2000, pp. 407-412. http://dx.doi.org/10.1046/j.1365-2842.2000.00508.x 